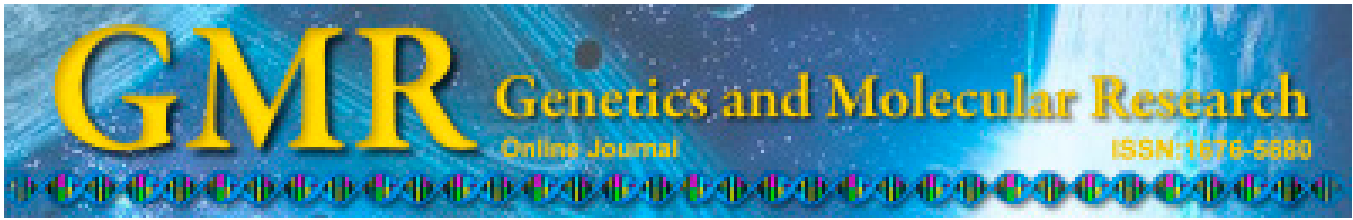

\title{
Molecular phylogenetics of the white-lipped peccary (Tayassu pecari) did not confirm morphological subspecies in northwestern South America
}

\author{
M. Ruiz-García ${ }^{1}$, M. Pinedo-Castro ${ }^{1}$, K. Luengas-Villamil ${ }^{1}$, C. Vergara ${ }^{1,2}$, \\ J.A. Rodriguez ${ }^{3}$ and J.M. Shostell ${ }^{4}$ \\ ${ }^{1}$ Laboratorio de Genética de Poblaciones-Biología Evolutiva, \\ Unidad de Genética, Departamento de Biología, Facultad de Ciencias, \\ Pontificia Universidad Javeriana, Bogotá, DC, Colombia \\ ${ }^{2}$ Instituto de Innovación en Biotecnología e Industria, \\ Unidad de Biotecnología Médica, Santo Domingo, Republica Dominicana \\ ${ }^{3}$ Instituto de Investigación de la Orinoquia Colombiana, \\ Facultad de Ciencias Básicas e Ingenierías, Universidad de Los Llanos, \\ Unillanos, Sede Barcelona, Colombia \\ ${ }^{4}$ Biology Department, Penn State University-Fayette, Uniontown, \\ PA, USA \\ Corresponding author: M. Ruiz-García \\ E-mail: mruiz@javeriana.edu.co / mruizgar@yahoo.es
}

Genet. Mol. Res. 14 (2): 5355-5378 (2015)

Received May 13, 2014

Accepted November 24, 2014

Published May 22, 2015

DOI http://dx.doi.org/10.4238/2015.May.22.6

\begin{abstract}
We sequenced the mitochondrial DNA (mtDNA) control region of 59 peccaries (44 white-lipped peccaries, Tayassu pecari, and 15 collared peccaries, Pecari tajacu). We also genotyped 3 DNA microsatellites from 78 white-lipped peccaries representing the 4 putative morphological subspecies (i.e., spiradens, aequatoris, pecari, and albirostris) present in northwestern South America (i.e., Colombia, Ecuador, Peru, and Bolivia). Our results showed:
\end{abstract}


1) the estimated diversity of the mtDNA control region in the $T$. pecari population was extremely high, whereas the average genetic diversity for the microsatellites was medium to high and similar to that observed in European pig breeds; 2) there was no significant genetic heterogeneity among the quoted putative morphological subspecies at the mitochondrial marker, but we did detect significant (although relatively small) genetic heterogeneity using microsatellites, indicating that $T$. pecari albirostris is a uniquely differentiated group; and 3 ) the phylogenetic mtDNA trees showed that haplotypes were intermixed independent of their "a priori" subspecies classification. In addition, the microsatellite assignation analyses yielded low percentages of well-classified individuals when the analysis considered the geographic morphology of the subspecies. Thus, the molecular results do not support the putative morphological subspecies of T. pecari in northwestern South America. Finally, our results did not detect clear historical demographic changes using the mtDNA control region sequences. These genetic results are discussed in the context of the ecological and social characteristics of T. pecari.

Key words: Tayassu pecari; Mitochondrial sequences; Microsatellites; Genetic heterogeneity; Demographic changes

\section{INTRODUCTION}

There are currently 3 recognized species of peccaries (Family Dicotylidae, Turner 1849, or Tayassuidae, Palmer 1897), all of which live in the Americas, although some fossil records have been discovered in Europe, Asia, and Africa. Following Wright (1998), these species are classified into 3 genera, including the white-lipped (Tayassu pecari), collared (Pecari tajacu), and Chacoan (Catagonus wagneri) peccaries. This last species was thought to have been extinct but was found in the Chaco region (i.e., Bolivia, Argentina, and Paraguay) in 1974 (Wetzel et al., 1975). Recently, Van Roosmalen et al. (2007) claimed the discovery of a new peccary species, P. maximus (giant peccary), in the area of the Aripuanã River in the interfluve of the Madeira and Tapajos Rivers within the central Brazilian Amazon based on the analysis of 3 skulls and 5 skins. The authors sequenced the mitochondrial DNA (mtDNA) control region and 2 nuclear genes from one of these skins, and they concluded that this new species diverged from the collared peccary around 1.0-1.2 mya. However, Gongora et al. (2011) claimed that no clear evidence exists in favor of this newly reported peccary species because the individual sequenced by Van Roosmalen et al. (2007) was clustered within the Brazilian $P$. tajacu mitochondrial lineage.

Benirschke et al. (1985) claimed that chromosomal reduction in peccaries showed that $P$. $\operatorname{tajacu}(2 \mathrm{~N}=30)$ was the most primitive peccary species, and T. pecari $(2 \mathrm{~N}=26)$ and $C$. wagneri $(2 \mathrm{~N}=20)$ were derived species $(C$. wagneri was indicated as the most recently derived species). In contrast, Todd (1985) determined that the chromosomal evolution of peccaries occurred via fissioning of the chromosomes and, thus, $C$. wagneri is the most primitive species and P. tajacu is the most recent. Theimer and Keim (1998) analyzed the $m t C y t$-b gene from the 3 extant peccary species and determined that $C$. wagneri and T. pecari conformed a 
clade, whereas $P$. tajacu conformed a separate lineage. The temporal split between Categonus and Tayassu was estimated to have occurred around 1.7-2.0 mya, concomitant with the colonization of the Tayassuidae of South America. The divergence of the Pecari lineage was estimated to be older, around 3.2-7.4 mya, during the Miocene, thus supporting that these 2 peccary lineages diverged in North America before South American peccary colonization.

These peccary species are some of the most important sources of animal proteins obtained from wild-caught animals in Latin America ("carne de monte" or "carne do mato") for the Indians and "colonos" populations of that area. In the Iquitos markets of Peru, 65 and $19.5 \%$ of the hunted meat sold was collared and white-lipped peccary meat, respectively. In fact, for some local Indian tribes (e.g., Mundurucú, Brazil; Guayakí, Paraguay; Mayas Lacandones, Chiapa, Mexico), T. pecari meat is the most important. Moreover, the skins are exported to make high-quality gloves. During the 1950s, 1960s, and 1970s, 200,000 peccary skins were annually exported from the Peruvian Amazon. In the $1980 \mathrm{~s}$, this value decreased to $\sim 50,000$ skins each year. The financial reward for each skin is $\sim$ US\$ 7-9 for the collared peccary and $\sim$ US\$ 3-5 for the white-lipped peccary. Thus, peccaries have high economic value.

The white-lipped peccary (pecarí labiado, chancho tropero, huangana, puerco de monte, báquiro careto, bidó, queixada) is distributed from Veracruz and Oaxaca in eastern and southern Mexico to the Entre Rios and Santiago del Estero Provinces in Argentina. This species mainly lives in the neotropical rain forests throughout Latin America, but it also inhabits drier habits in the Colombian Eastern Llanos, Venezuelan savannah, and Paraguayan Gran Chaco. Herds of this species are larger than those of the collared peccaries, and they are composed of 50-300 individuals (Fragoso, 1999).

Mayer and Wentzel (1987) considered the existence of 5 subspecies of T. pecari. 1) T. pecari ringens, defined by Merriam in 1901, with type locality Azapote in Campeche, Mexico. This subspecies ranges from southern Mexico (Oaxaca, Chiapas, Campeche, and Quintana Roo) to northern Nicaragua, crossing Guatemala, Belize, and Honduras. Currently, it is extirpated in El Salvador. 2) T. pecari spiradens, described by Goldman in 1912, has type locality Sipurio, Sixaola, Limón, Costa Rica. Its distribution ranges from southern Guatemala, Costa Rica, and Panama to northwestern Colombia (including the Atlantic and Pacific coasts of this country near the Western portion of the Central Andean Cordillera). 3) T. pecari aequatoris, primarily described by Lonnberg in 1921, has type locality Gualea, Pichincha, Ecuador. This subspecies has the most restricted geographic distribution of all the white-lipped peccaries. It is distributed in southwestern Colombia (Cauca and Nariño Departments) and northwestern Ecuador (Esmeraldas, Manabí, and Pichincha Provinces). 4) T. pecari beebei, described by Anthony in 1921, has type locality Kartabo, Guyana. The distribution of this subspecies includes the majority of South America north of the Amazon River; it covers the eastern and southeastern Amazon in Colombia; northeastern Amazon in Peru, Venezuela, Guyana, Surinam, and French Guyana; and northern Amazon in Brazil. 5) T. pecari pecari was first described by Link in 1795. The distribution of this subspecies occurs south of the Amazon River, including the southern Peruvian Amazon, Bolivian Amazon, all of the Brazilian territory south of the Amazon River, Paraguay, and northern Argentina (Santiago del Estero and Entre Rios Provinces as its southern limit). This subspecies was previously distributed in Uruguay, but it is now considered extinct in this area it was last observed and reported in Uruguay in 1890.

Grubb and Groves (1996) adopted another classification scheme. They found that $T$. pecari beebei is a synonym for T. pecari pecari, and the most southern subspecies (which has the widest geographic range) should be designated as T. pecari albirostris (defined by Illiger 
in 1815 from a specimen in Paraguay). Thus, they consider 5 sub-species, named T. pecari ringens, T. pecari spiradens, T. pecari aequatoris, T. pecari pecari, and T. pecari albirostris. This is the classification scheme that we employed in the current work.

To analyze, from a molecular perspective, how some of these putative morphological subspecies of T. pecari are sustained, we employed 2 types of molecular markers. First, we sequenced the mtDNA control region (D-loop), which is a portion that evolves particularly rapidly and, thus, allows fine-scale resolution of population structure and microevolutionary divisions. Second, we analyzed some short tandem repeat polymorphisms, or microsatellites, which are composed of tandem, repetitive units 2-6 bp in length. Microsatellites are randomly distributed, highly polymorphic, and frequently found inside eukaryotic genomes. The small amount of DNA needed for these molecular analyses has led to a strong incorporation of molecular techniques in the study of the dynamics and systematics of population biology.

The main aims of the current study were as follows: 1) to determine if there is some agreement between the putative recognized morphological T. pecari subspecies from northwestern South America and the molecular results obtained herein; 2) to estimate the levels of genetic diversity for these T. pecari populations using both mtDNA and microsatellites; and 3 ) to determine, using the mtDNA sequences, some aspects of the demographics and genetic history for the T. pecari population in northwestern South America.

\section{MATERIAL AND METHODS}

\section{Sampling localities}

Two sets of T. pecari samples were employed in this study, one for mtDNA and another for microsatellites (Figure 1). For analysis of the mtDNA control region sequences, we analyzed 44 samples from $T$. pecari. To represent $T$. pecari spiradens, we sampled and sequenced one specimen from Riosucio, Chocó (Colombia). For T. pecari aequatoris, we analyzed one individual from Manabí Province (Ecuador). T. pecari was represented by 14 individuals (one from Tarapacá, Amazon Department, Colombia; 7 from Amacayacu National Park near Leticia in the Amazon Department of Colombia; 4 from the Nanay River, near Iquitos, Peru; and

2 from Santa Clotilde, Curaray River, Peru). To represent $T$. pecari albirostris, we analyzed 28 specimens [17 from 3 populations (Exaltación, Puerto Siles, and Alejandria), Mamoré River, Bolivia; 3 from Yurimaguas, Huallaga River, Peru; 4 from Sierra Escalera, near Tarapoto, San Martin Department, Peru; and 4 from Masisea, near Pucallpa, Ucayali River, Peru]. For the outgroup, we used 15 samples of $P$. tajacu. Of these 15 samples, one sequence was obtained from GenBank (accession No. AY546541), one sample represented the P. tajacu tajacu subspecies (Tabatinga, Amazon River, Brazil), and 13 samples represented the P. tajacu patira subspecies (3 from Villavicencio, Meta, Colombia; 7 from the Nanay River, Peru; one from Yurimaguas, Huallaga River, Peru; one from the Curaray River, Peru; and one from Moyobamba, San Martin Department, Peru).

For the microsatellite markers, we analyzed 78 T. pecari individuals (Figure 1). Of the 78, 3 were T. pecari spiradens (from Riosucio, Chocó, Colombia), 2 were T. pecari aequatoris from Manabí Province (Ecuador), and 37 were T. pecari from Colombia and Peru (2 close to Florencia, Caquetá Department, Colombia; 2 from Tarapacá, Amazonas Department, Colombia; 10 from Amacayacu National Park, Amazonas Department, Colombia; 2 from Puerto Inirida, Guainia Department, Colombia; 10 from Putumayo River, Putumayo Department, Co- 
lombia; and 11 from Nanay River in the Loreto Department, Peru). The remaining 36 samples were $T$. pecari albirostris from the 3 previously mentioned Bolivian localities adjacent to the Mamoré River.

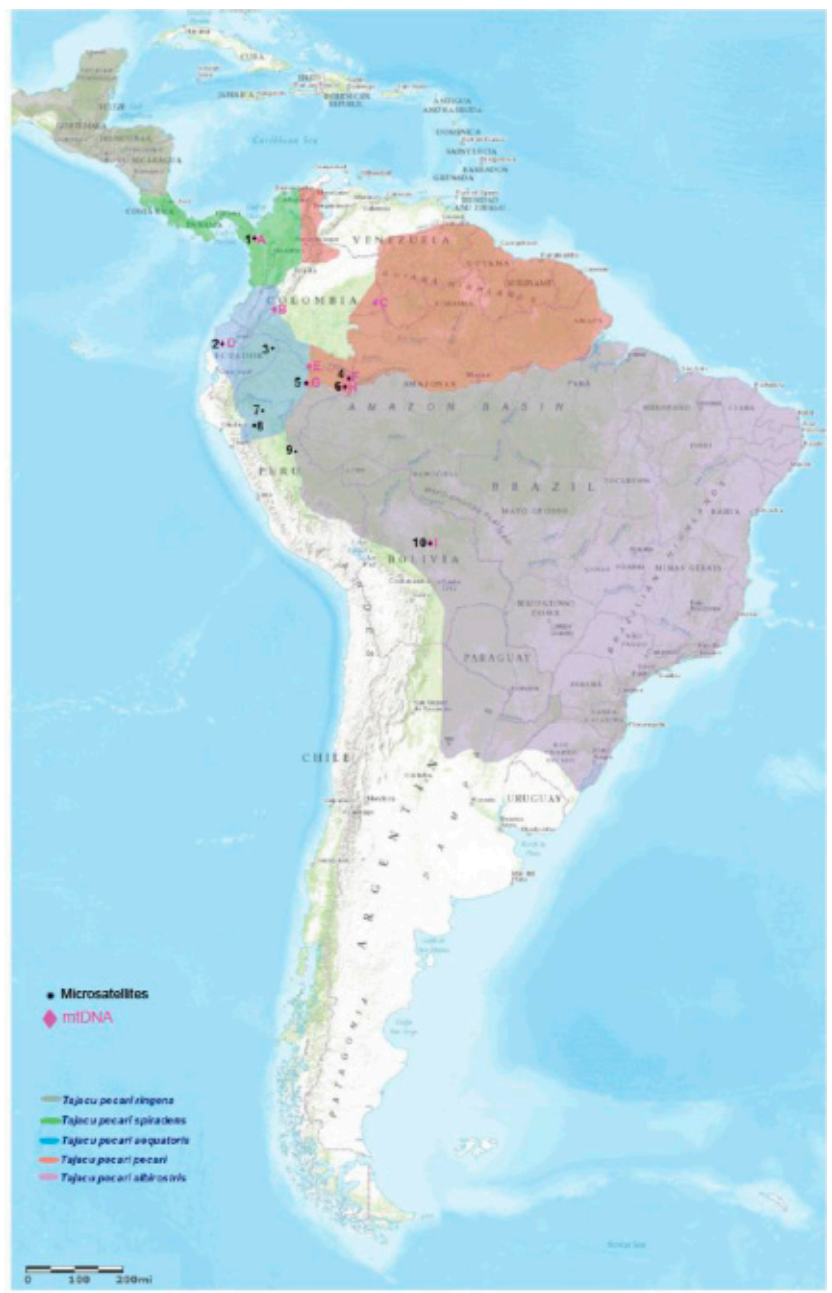

Figure 1. Map of South America indicating the locations where Tayassu pecari individuals were sampled and the distribution of the different subspecies. The geographic points sampled for the microsatellite analysis were as follows: $\mathrm{A}=$ Rio Sucio, Chocó Department, Colombia $(\mathrm{N}=3)$; $\mathrm{B}=$ Florencia, Caquetá Department, Colombia $(\mathrm{N}=2) ; \mathrm{C}=$ Puerto Inírida, Guainía Department, Colombia $(\mathrm{N}=2) ; \mathrm{D}=$ Manabí Province, Ecuador $(\mathrm{N}=2) ; \mathrm{E}$ $=$ Putumayo River, Colombia $(\mathrm{N}=10) ; \mathrm{F}=$ Tarapacá, Amazonas Department, Colombia $(\mathrm{N}=2)$; Nanay River, Loreto Department, Perú $(\mathrm{N}=11) ; \mathrm{H}=$ Amacayacu National Park, Amazonas Department, Colombia $(\mathrm{N}=10)$; and $\mathrm{I}=$ Mamoré River, Beni Department, Bolivia $(\mathrm{N}=36)$. The geographic points sampled for the mitochondrial gene analysis were as follows: $1=$ Rio Sucio, Chocó Department, Colombia $(\mathrm{N}=1) ; 2$ Manabí Province, Ecuador $(\mathrm{N}=1) ; 3=$ Santa Clotilde, Curaray River, Loreto Department, Perú $(\mathrm{N}=2) ; 4$ = Tarapacá, Amazonas Department, Colombia ( $\mathrm{N}=1) ; 5=$ Nanay River, Loreto Department, Perú $(\mathrm{N}=4) ; 6=$ Amacayacu National Park, Amazonas Department, Colombia ( $=7) ; 7=$ Yurimaguas, Huallaga River, Perú $(\mathrm{N}=3) ; 8=$ Tarapoto, San Martín Department, Perú $(\mathrm{N}=4) ; 9=$ Masisea River, Ucayali Department, Perú $(\mathrm{N}=4)$; and $10=$ Mamoré River, Beni Department, Bolivia $(\mathrm{N}=17)$. 


\section{Molecular markers}

\section{$m t D N A$}

DNA from the muscle and skin were obtained from the peccaries analyzed in this study via phenol-chloroform. Additionally, we obtained DNA from the hair (with follicles) using 10\% Chelex resin (Walsh et al., 1991). Published primer pairs were used to amplify $\sim 1120$ base pairs (bp) of the mtDNA control region (Kim et al., 2002). Polymerase chain reactions (PCRs) were performed in $50-\mu \mathrm{L}$ reaction volumes, containing $50 \mathrm{mM} \mathrm{KCl}, 4 \mu \mathrm{L} 10 \mathrm{X}$ buffer, $0.1 \%$ Triton $\mathrm{X}-100,3 \mathrm{mM} \mathrm{MgCl}, 1 \mathrm{mM}$ dNTPs, $1 \mu \mathrm{M}$ of each primer, 2 units Taq DNA polymerase, $13.5 \mu \mathrm{L} \mathrm{H}_{2} \mathrm{O}$, and $2 \mu \mathrm{L}$ DNA $(50-100 \mathrm{ng} / \mu \mathrm{L})$. PCR conditions included an initial denaturation at $95^{\circ} \mathrm{C}$ for $5 \mathrm{~min}$; followed by 10 cycles of $1 \mathrm{~min}$ at $95^{\circ} \mathrm{C}, 1 \mathrm{~min}$ at $64^{\circ} \mathrm{C}$, and 2 min at $72^{\circ} \mathrm{C} ; 25$ cycles of $1 \mathrm{~min}$ at $95^{\circ} \mathrm{C}, 1 \mathrm{~min}$ at $60^{\circ} \mathrm{C}$, and $2 \mathrm{~min}$ at $72^{\circ} \mathrm{C}$; and a final extension of $10 \mathrm{~min}$ at $72^{\circ} \mathrm{C}$.

We used the molecular weight marker $\phi X 174$ DNA digested with HindIII and HinfI to check all amplifications, including the positive and negative controls, on $2 \%$ agarose gels. We purified the amplified samples with membrane-binding spin columns (Qiagen product), directly sequenced the double-stranded DNA in a 377A (ABI) automated DNA sequencer, sequenced the samples in both directions, and then repeated the sequencing of each sample to ensure accuracy.

\section{Microsatellites}

Three porcine microsatellite primer pairs (i.e., IGF1, SW857, and SW951; Moran, 1993) were applied to the 78 T. pecari individuals analyzed. IGF1 was placed at the 5th chromosome and ranged from 194 to $210 \mathrm{bp}$, whereas $S W 857$ was placed at the 14th chromosome and ranged from 144 to $162 \mathrm{bp}$. SW951 was placed at the 10th chromosome and ranged in size from 124 to $133 \mathrm{bp}$.

The final PCR volume and reagent concentrations for the DNA extraction from the muscle and skin were $25 \mu \mathrm{L}$, with $2.5 \mu \mathrm{L} \mathrm{MgCl}_{2} 3 \mathrm{mM}, 2.5 \mu \mathrm{L}$ buffer $10 \mathrm{X}, 0.5 \mu \mathrm{L}$ dNTPs $(0.2 \mathrm{mM}), 1 \mu \mathrm{L}$ of each primer (forward and reverse; 4 pmol), $14.5 \mu \mathrm{L} \mathrm{H}_{2} \mathrm{O}, 2 \mu \mathrm{L} 50-100 \mathrm{ng} /$ $\mu \mathrm{L}$, DNA, and $1 \mathrm{U}$ Taq polymerase per reaction $(1 \mu \mathrm{L})$. For the PCRs using hairs, the overall volume was $50 \mu \mathrm{L}$, with $20 \mu \mathrm{L}$ DNA and two-fold amounts of $\mathrm{MgCl}_{2}$, buffer, dNTPs, primers, and Taq polymerase.

All PCRs were carried out in a Perkin Elmer GeneAmp PCR System 9600 Thermal Cycler for $5 \mathrm{~min}$ at $95^{\circ} \mathrm{C}, 301-\mathrm{min}$ cycles at $94^{\circ} \mathrm{C}, 1 \mathrm{~min}$ at $55^{\circ} \mathrm{C}, 1 \mathrm{~min}$ at $72^{\circ} \mathrm{C}$, and 5 min at $72^{\circ} \mathrm{C}$. The amplification products were kept at $4^{\circ} \mathrm{C}$ until use. The PCR amplification products were run on denatured $6 \%$ polyacrylamide gels in a Hoefer SQ3 sequencer vertical chamber. Depending on the size of the markers analyzed and the presence of 35 $\mathrm{W}$ as a constant, the gels were stained with $\mathrm{AgNO}_{3}$ (silver nitrate) after 2-3 h of migration. The molecular weight markers used were $\phi 174$ (cut with HindIII) and HinfI. The PCRs were repeated 3 times for DNA extracted from the hairs in order to confirm the genotypes obtained from this material. Therefore, allelic dropout was highly improbable. The existence of null alleles cannot be totally excluded, however, which could increase the number of false homozygous genotypes. Nevertheless, it is improbable that all loci were affected in the same way. 


\section{Data analyses}

\section{$m t D N A$}

\section{Genetic diversity and heterogeneity analyses}

The statistical values used to determine genetic diversity were: the number of polymorphic sites $(S)$, haplotypic diversity $\left(H_{\mathrm{d}}\right)$, nucleotide diversity $(\mathrm{p})$, and q statistic by sequence. Several procedures were carried out to estimate genetic heterogeneity and gene flow among the diverse putative morphological T. pecari in this study. One procedure was applied to the haplotypic frequencies ( $G_{\mathrm{ST}}$ statistic; Nei, 1973), and other genetic heterogeneity statistical tests were applied to the nucleotide sequences $\left(g_{\mathrm{ST}}, N_{\mathrm{ST}}\right.$, and $F_{\mathrm{ST}}$ statistics). Additionally, the tests $H_{\mathrm{ST}}, K_{\mathrm{ST}}, K_{\mathrm{ST}}{ }^{*}, Z$, and $Z^{*}, S_{\mathrm{nn}}$, and $\chi^{2}$ (on the haplotypic frequencies with permutation tests of 10,000 replicates) were performed (Hudson, 2000). These genetic diversity and heterogeneity statistical values were estimated using the programs DNAsp 5.1 and Arlequin 3.5.1.2.

\section{Phylogenetic analyses}

The sequence alignments were carried out manually using DNA Alignment (Fluxus Technology Ltd.). Modeltest (Posada and Crandall, 1998) and Mega 5.1 (Tamura et al., 2011) were applied to determine the best evolutionary mutation model for the 59 sequences analyzed. Three criteria were employed to determine the best evolutionary nucleotide model for the maximum likelihood tree obtained, including Bayesian information criteria (BIC), Akaike information criteria (AIC), and the hierarchical likelihood ratio test $(\operatorname{lnL})$.

We obtained maximum likelihood estimates of transition/transversion bias as well as maximum likelihood estimates of gamma parameter for site rates for the best evolutionary mutation models obtained (Tamura et al., 2011). The phylogenetic trees were obtained using the means of 2 different procedures: 1) neighbor-joining tree with the Tamura 3P genetic distance and 2) maximum likelihood tree with the general time reversible (GTR) model. The trees were constructed using PAUP*4.0b8 and MEGA 5.1.

\section{Demographic changes}

We used the following procedures to determine possible historical population changes for the northwest South American T. pecari population. 1) The mismatch distribution (pairwise sequence differences) was obtained following the method of Rogers and Harpending (1992). We used the raggedness $(\mathrm{rg})$ statistic to determine the similarity between the observed and theoretical curves. 2) We used Fu and Li's $D$ and $F$ tests (Fu and Li, 1993), Fu's $F_{\mathrm{S}}$ statistic (Fu, 1997), Tajima's $D$ test (Tajima, 1989), and the R2 statistic of Ramos-Onsins and Rozas (2002) to determine possible population size changes in the northwestern South American T. pecari population analyzed. A total of 10,000 coalescence replicates were used to test the significance of the statistical values calculated. 


\section{Microsatellites}

The expected heterozygosity $\left(H_{\mathrm{E}}\right)(\mathrm{Nei}, 1973)$ and its standard deviation, and the mean allele number $\left(N_{\mathrm{A}}\right)$ and its standard deviation were calculated for the whole T. pecari sample analyzed and the 2 samples representing $T$. pecari pecari and T. pecari albirostris.

We used the GeneClass 2 program to develop diverse assignment analyses. The different analyses were performed using 2 Bayesian (Rannala and Mountain, 1997; Badouin and Lebrun, 2000), one frequency (Paetkau et al., 1995), and 2 genetic distances (i.e., standard genetic distance; Cavalli-Sforza and Edwards, 1967 genetic distance; and $\delta \mu^{2}$ genetic distance) procedures. The assignation analyses were carried out without simulations and estimating probabilities of belonging, or exclusion, of the individuals to the morphological putative subspecies where they were "a priori" assigned $(\mathrm{P}<0.05)$. In addition, some assignation analyses were performed with 10,000 resampling simulations by means of the Monte Carlo technique, and the procedures of Paetkau et al. (2004), and Rannala and Mountain (1997). Additionally, we estimated the possible existence of first-generation migrants in the different $T$. pecari subspecies considered. In order to do this, we used the Bayesian, frequency, and genetic distance procedures mentioned above without simulations. To determine this, we considered the relationship:

$$
\mathrm{L}=\text { Lhome/Lmax }
$$

which is the ratio of the likelihood computed from the population where the individual was sampled (Lhome) over the highest likelihood value among all population samples, including the population where the individual was sampled (Lmax; Paetkau et al., 2004).

Finally, another assignment analysis was applied to the 78 multilocus genotype $T$. pecari profiles obtained. This assignment analysis was applied using Structure 2.3 (Falush et al., 2007), which employs Markov Chain Monte Carlo procedures and the Gibbs sampler, uses multilocus genotypes to infer population structure, and simultaneously assigns individuals to specific populations. The model considers $K$ populations, where $K$ may be unknown, and the individuals are assigned tentatively to one population or jointly to $\geq 2$ populations (if their genotypes are considered admixed). Two analyses were carried out. First, we considered the admixture model, wherein the individuals may have mixed ancestry. This model does not consider any prior population information to assist with clustering (USEPOPINF $=0$ ). In addition, a was inferred (Dirichlet parameter for degree of admixture; with an initial value of $\mathrm{a}=1$ ) using uniform priors for a (its value was the same for all populations). The maximum value of this parameter was 10 . Allele frequencies were correlated among populations, assuming different values of $F_{\mathrm{ST}}$ for each population, with a prior mean $F_{\mathrm{ST}}$ of 0.09 and a constant value of $1=1$. We revealed the presence of the most probable number of gene pools by using the increasing likelihood method. The second analysis was undertaken with a model that incorporates informative geographic and subspecies priors to assist with the clustering of weakly structured data in order to determine migrants or detect slightly different populations (USEPOPINF $=1$ ). Furthermore, in this case, in order to apply the same conditions to that of the previous case, we introduced LocPrior $=1$, Gensback $=2$, and Migprior $=0.05$. The program was run with 1,000,000 iterations after a burn period of 100,000 iterations for each analysis. Each analysis was performed twice with convergent results. 


\section{RESULTS}

\section{Gene diversity}

\section{$m t D N A$}

The gene diversity for the overall T. pecari sample analyzed yielded 44 different haplotypes. There were 351 polymorphic sites, the nucleotide diversity was $\mathrm{p}=0.0882 \pm 0.019$, and the q per sequence was $80.69 \pm 18.55$. Thus, the overall levels of genetic diversity for $T$. pecari were very high. For the 2 putative subspecies, for which the number of samples was sufficient, the gene diversity levels were obtained. The T. pecari pecari samples showed 268 polymorphic segregating sites, 14 haplotypes, $\mathrm{p}=0.0597 \pm 0.0291$, and a q per sequence of $84.273 \pm 26.50$. On the other hand, T. pecari albirostris samples yielded 312 polymorphic segregating sites, 28 haplotypes, $\mathrm{p}=0.1044 \pm 0.0229$, and a q per sequence of $80.176 \pm 20.603$. Therefore, for both putative subspecies, as well as for the overall sample, the levels of genetic diversity were extremely high for this mitochondrial marker.

\section{Microsatellites}

Table 1 shows the different statistical values for genetic diversity of the 3 microsatellites studied. Globally, we found 10, 21, and 6 alleles at the IGFI (224-246 bp), SW857 (117$167 \mathrm{bp}$ ), and $S W 951$ (105-131 bp) loci, respectively. The overall $H_{\mathrm{E}}$ was 0.667 . The samples representing T. pecari pecari showed the highest average $N_{\mathrm{A}}(10.667 \pm 3.018)$, followed by $T$. pecari albirostris $(5.667 \pm 1.155)$. A similar situation was found for the mean $H_{\mathrm{E}}$. Once again, T. pecari pecari showed the highest value $\left(H_{\mathrm{E}}=0.616 \pm 0.392\right)$, followed by $T$. pecari albirostris $\left(H_{\mathrm{E}}=0.528 \pm 0.143\right)$. The values for $T$. pecari aequatoris and $T$. pecari spiradens were not realistic because an insufficient number of samples were analyzed for these putative taxa. The average $N_{\mathrm{A}}$ was significantly higher for T. pecari pecari than that for $T$. pecari albirostris, but there was no significant difference in the mean $H_{\mathrm{E}}$.

Table 1. Gene diversities $\left(N_{\mathrm{A}}=\right.$ number of alleles; $H_{\mathrm{E}}=$ expected heterozygosity; total values with standard deviations) at 3 porcine microsatellites (i.e., $I G F 1, S W 857$, and $S W 951$ ) applied to the white-lipped peccary (Tayassu pecari) representing the 4 morphological subspecies present in northwestern South America.

\begin{tabular}{lllll}
\hline T. pecari subspecies & IGFI & SW857 & SW951 & $\begin{array}{l}\text { Average values at the } \\
\text { 3 microsatellites for each subspecies }\end{array}$ \\
\hline T. pecari albirostris & $N_{\mathrm{A}}=5$ & $N_{\mathrm{A}}=7$ & $N_{\mathrm{A}}=5$ & $N_{\mathrm{A}}=5.667 \pm 1.155$ \\
& $H_{\mathrm{E}}=0.639$ & $H_{\mathrm{E}}=0.579$ & $H_{\mathrm{E}}=0.367$ & $H_{\mathrm{E}}=0.528 \pm 0.143$ \\
T. pecari aequatoris & $N_{\mathrm{A}}=1$ & $N_{\mathrm{A}}=2$ & $N_{\mathrm{A}}=1$ & $N_{\mathrm{A}}=1.000 \pm 1.000$ \\
& $H_{\mathrm{E}}=0.000$ & $H_{\mathrm{E}}=0.500$ & $H_{\mathrm{E}}=0.000$ & $H_{\mathrm{E}}=0.250 \pm 0.273$ \\
T. pecari spiradens & $N_{\mathrm{A}}=2$ & $N_{\mathrm{A}}=1$ & $N_{\mathrm{A}}=2$ & $N_{\mathrm{A}}=1.667 \pm 0.577$ \\
& $H_{\mathrm{E}}=0.533$ & $H_{\mathrm{E}}=0.000$ & $H_{\mathrm{E}}=0.333$ & $H_{\mathrm{E}}=0.289 \pm 0.269$ \\
T. pecari pecari & $N_{\mathrm{A}}=10$ & $N_{\mathrm{A}}=20$ & $N_{\mathrm{A}}=2$ & $N_{\mathrm{A}}=10.667 \pm 9.018$ \\
& $H_{\mathrm{E}}=0.798$ & $H_{\mathrm{E}}=0.883$ & $H_{\mathrm{E}}=0.166$ & $H_{\mathrm{E}}=0.616 \pm 0.392$ \\
Average for the 4 & $N_{\mathrm{A}}=4.5$ & $N_{\mathrm{A}}=7.5$ & $N_{\mathrm{A}}=2.25$ & \\
subspecies at each marker & $H_{\mathrm{E}}=0.493$ & $H_{\mathrm{E}}=0.490$ & $H_{\mathrm{E}}=0.289$ & \\
& & &
\end{tabular}




\section{Genetic heterogeneity}

\section{$m t D N A$}

Genetic heterogeneity statistical values (Table 2$)$ were not significant for the mitochondrial sequences. In fact, all gene flow $\left(N_{\mathrm{m}}\right)$ estimates were very high $\left(N_{\mathrm{mGst}}=168 ; N_{\mathrm{mNST}}\right.$ $=12.51$ ). Thus, no evidence of significant molecular genetic heterogeneity was found, which did not agree with the supposed putative morphological subspecies.

Table 2. Diverse genetic heterogeneity statistics at the mitochondrial DNA (mtDNA) control region gene for the 4 Tayassu pecari subspecies studied; $\mathrm{df}=$ degrees of freedom. No values were statistically significant. All gene flow estimates $\left(N_{\mathrm{m}}\right)$ were very high.

\begin{tabular}{lcccc}
\hline Statistics & Value & Prob & Statistics & $N_{\mathrm{m}}$ \\
\hline$\chi^{2}$ & $42.0(41 \mathrm{df})$ & 0.4274 & $G_{\mathrm{ST}}=0.0029$ & 168.00 \\
$H_{\mathrm{st}}$ & 0.0 & 1.0000 & $\gamma_{\mathrm{ST}}=0.0355$ & 13.56 \\
$K_{\mathrm{st}}$ & 0.01338 & 0.1005 & $N_{\mathrm{sT}}=0.0384$ & 12.51 \\
$K_{\mathrm{st}}{ }^{*}$ & 0.00211 & 0.2512 & $F_{\mathrm{ST}}=0.0301$ & \\
$Z^{*}$ & 426.98593 & 0.2050 & & \\
$S_{\mathrm{nn}}$ & 5.76165 & 0.3463 & & \\
\hline
\end{tabular}

\section{Microsatellites}

When the 4 putative subspecies were simultaneously analyzed for exact $\mathrm{G}$ tests at the 3 microsatellites, all of them showed significant genetic heterogeneity (IGF1: $\mathrm{P}=$ 0.0000001; SW857: $\mathrm{P}=0.0000001 ; S W 951: \mathrm{P}=0.0074$; all simultaneously: infinite, $\mathrm{df}=$ 6). Table 3 displays the values of $F_{\mathrm{ST}}$ and $R_{\mathrm{ST}}$. Both $I G F 1$ and $S W 857$ yielded significant $F_{\mathrm{ST}}$ values $\left(I G F 1: F_{\mathrm{ST}}=0.103, \mathrm{P}<0.001 ; S W 857: F_{\mathrm{ST}}=0.147, \mathrm{P}<0.001\right)$, whereas $S W 951$ did not show significant genetic heterogeneity when the Bonferroni correction $\left(\alpha^{\prime}=0.016\right)$ was applied $\left(F_{\mathrm{ST}}=0.019 ; \mathrm{NS}\right)$.

Table 3. Genetic heterogeneity values of the $F_{\mathrm{ST}}$ (and probabilities) and $R_{\mathrm{ST}}$ statistics at 3 microsatellites (i.e., $I G F 1, S W 857$, and $S W 951$ ) analyzed among the 4 morphological subspecies of Tayassu pecari in northwestern South America. *Significant with $\alpha$ ' 0.016 (probability with Bonferroni correction).

\begin{tabular}{lclc}
\hline Microsatellite & $F_{\mathrm{ST}}$ & Probability & $R_{\mathrm{ST}}$ \\
\hline IGF1 & 0.103 & $\mathrm{P}<0.001^{*}$ & 0.151 \\
SW857 & 0.147 & $\mathrm{P}<0.001^{*}$ & 0.303 \\
SW951 & 0.019 & $\mathrm{P}<0.02$ & 0.000 \\
Average & 0.111 & $\mathrm{P}<0.001^{*}$ & Weighted procedure: 0.245 \\
& & & Goodman procedure: 0.156 \\
& & & Unweighted procedure: 0.149 \\
\hline
\end{tabular}

The use of the exact $\mathrm{G}$ tests for subspecies pairs showed that all the pairs involving T. pecari albirostris were significant (T. pecari albirostris-T. pecari aequatoris: $\chi^{2}=33.424$, $\mathrm{df}=4, \mathrm{P}<0.000001 ;$ T. pecari albirostris-T. pecari spiradens: $\chi^{2}=$ infinite, $\mathrm{df}=6, \mathrm{P}<$ 0.000000001; T. pecari albirostris- T. pecari pecari: $\chi^{2}=$ infinite, $\mathrm{df}=6, \mathrm{P}<0.00000001$ ). In contrast, the values relating T. pecari pecari, T. pecari aequatoris, and T. pecari spiradens were not significant (T. pecari pecari-T. pecari aequatoris: $\chi^{2}=11.746, \mathrm{df}=4, \mathrm{P}<0.019 ; T$. 
pecari albirostris-T. pecari spiradens: $\chi^{2}=12.319, \mathrm{df}=6, \mathrm{P}<0.055 ;$ T. pecari aequatoris- . pecari spiradens $\chi^{2}=5.279, \mathrm{df}=4, \mathrm{P}<0.259$; Bonferroni correction, $\alpha^{\prime}=0.0083$ ). Thus, the 3 microsatellites that we used helped to differentiate T. pecari albirostris from the other putative subspecies, but did not differentiate among $T$. pecari pecari, $T$. pecari aequatoris, and $T$. pecari spiradens, as was shown by the mitochondrial sequences. In fact, the level of gene flow among all of these putative morphological subspecies was high when we used the private allele model $\left(N_{\mathrm{m}}=5.14\right)$.

\section{Phylogenetic inferences}

\section{$m+D N A$}

The nucleotide frequencies ascertained in this study were $\mathrm{A}=32.95 \%, \mathrm{~T}=27.12 \%$, $\mathrm{C}=27.37 \%$, and $\mathrm{G}=12.56 \%$. The best evolutionary nucleotide model was GTR $(+\mathrm{G})(+\mathrm{I})$ for the 3 criteria employed $(\mathrm{BIC}=13,394.888, \mathrm{AIC}=12,639.548$, and $\operatorname{lnL}=-6224.341)$. The estimated transition/transversion bias $(R)$ was 5.5, assuming a GTR model. The maximum Log likelihood for this computation was -7758.673 . The estimated value of the shape parameter for the discrete gamma distribution was 1.536 under the GTR model $(+\mathrm{G})$. The maximum Log likelihood for this computation was -7602.293 .

Both the maximum likelihood and neighbor-joining trees showed reciprocal monophyly between T. pecari and P. tajacu (Figure 2). In addition, both trees showed 3 robust clades within T. pecari; we named them clades I (69-94\% bootstrap), II (93-100\%), and III (81-82\%). Only 3 individuals changed their positions in both trees (2 Bolivian exemplars and one Peruvian exemplar from Tarapoto). No correlation was established among the putative morphological subspecies and these 3 well-defined molecular clades. In clade I, we found individuals of $T$. pecari pecari from the Colombian and Peruvian Amazon and T. pecari albirostris from Bolivia and southern Peru. Clade II contained exemplars of T. pecari pecari from the Colombian and Peruvian Amazon, one individual of T. pecari aequatoris from Ecuador, one individual of T. pecari spiradens from the Colombian Choco, and individuals of T. pecari albirostris from the Bolivian and Peruvian Amazon. In clade III, we found only Peruvian animals, but they represented both subspecies (i.e., T. pecari pecari and T. pecari albirostris). Therefore, no morphological subspecies were found at the molecular level, and the 3 molecular lineages were found living in sympatry in different areas.

\section{Microsatellites}

The results obtained via GeneClass 2.0 showed that only $55.13\left(\delta \mu^{2}\right.$ genetic distance) to $64.10 \%$ (Cavalli-Sforza and Edwards 1967; genetic distance) of the individuals analyzed were classified into their putative morphological subspecies (Table 4). For example, within $T$. pecari albirostris in one procedure (Rannala and Mountain, 1997; see other cases in Table 4), $11.11 \%(4 / 36)$ of the exemplars were classified as T. pecari pecari. Within T. pecari aequatoris, $50 \%(1 / 2)$ of individuals were added to T. pecari spiradens. Within T. pecari spiradens, $33.33 \%(1 / 3)$ of the animals studied were identified as T. pecari albirostris. Additionally, within T. pecari pecari, 16.22 (6/37), 16.22 (6/37), and 35.13\% (13/37) of specimens were classified as T. pecari spiradens, T. pecari aequatoris, and T. pecari albirostris, respectively. Henceforth, as it was determined via phylogenetic trees for the mitochondrial gene, the microsatellite results were not consistent for the proposed morphological subspecies. 


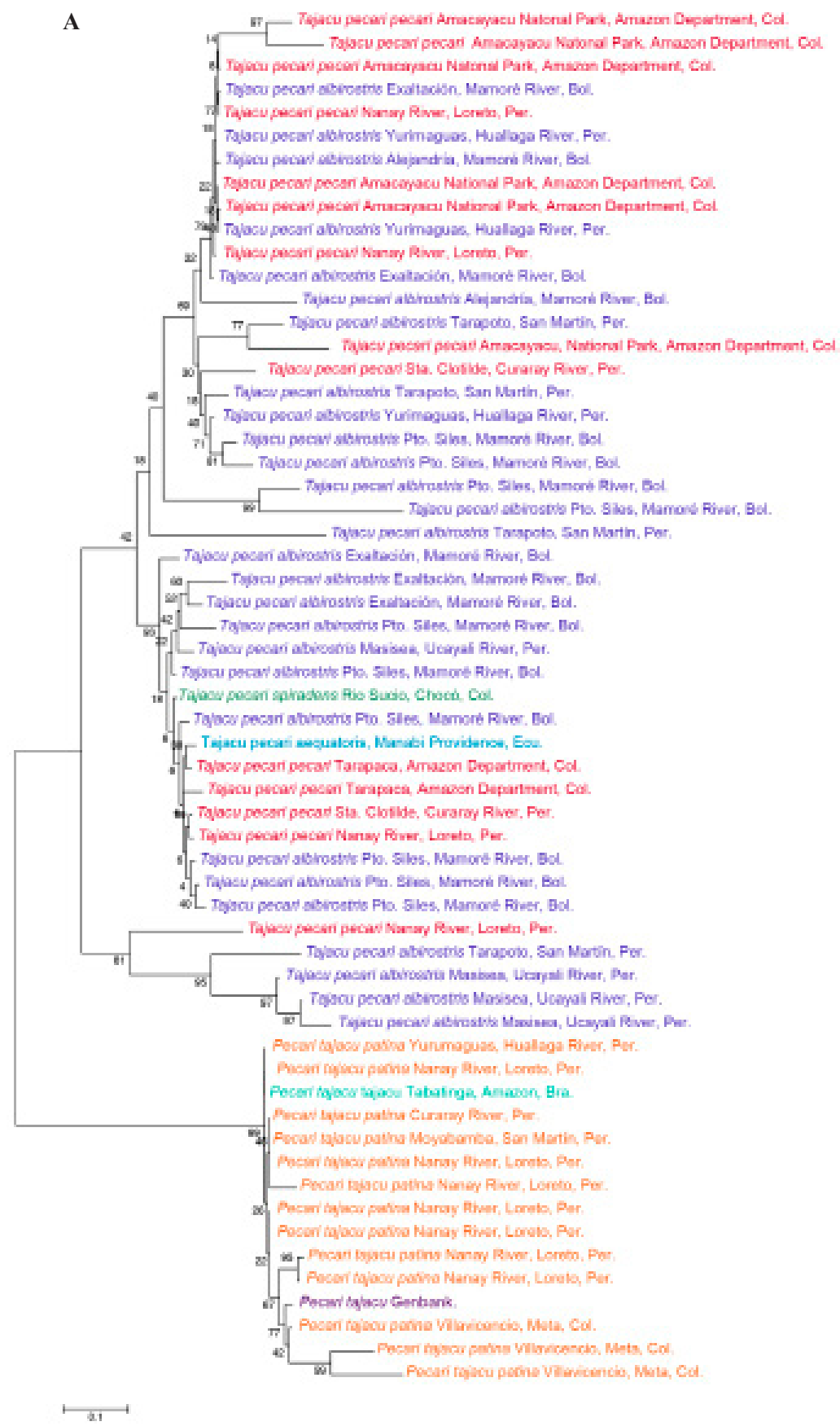

Figure 2. Maximum likelihood (A) and neighbor-joining (B) (with the Tamura 3P genetic distance) trees of the Tayassu pecari individuals sequenced at the mitochondrial DNA control region. Bootstrap percentages are indicated at the nodes. The different $T$. pecari subspecies analyzed are indicated by the different colors.

Continued on next page 
Figure 1. Continued.

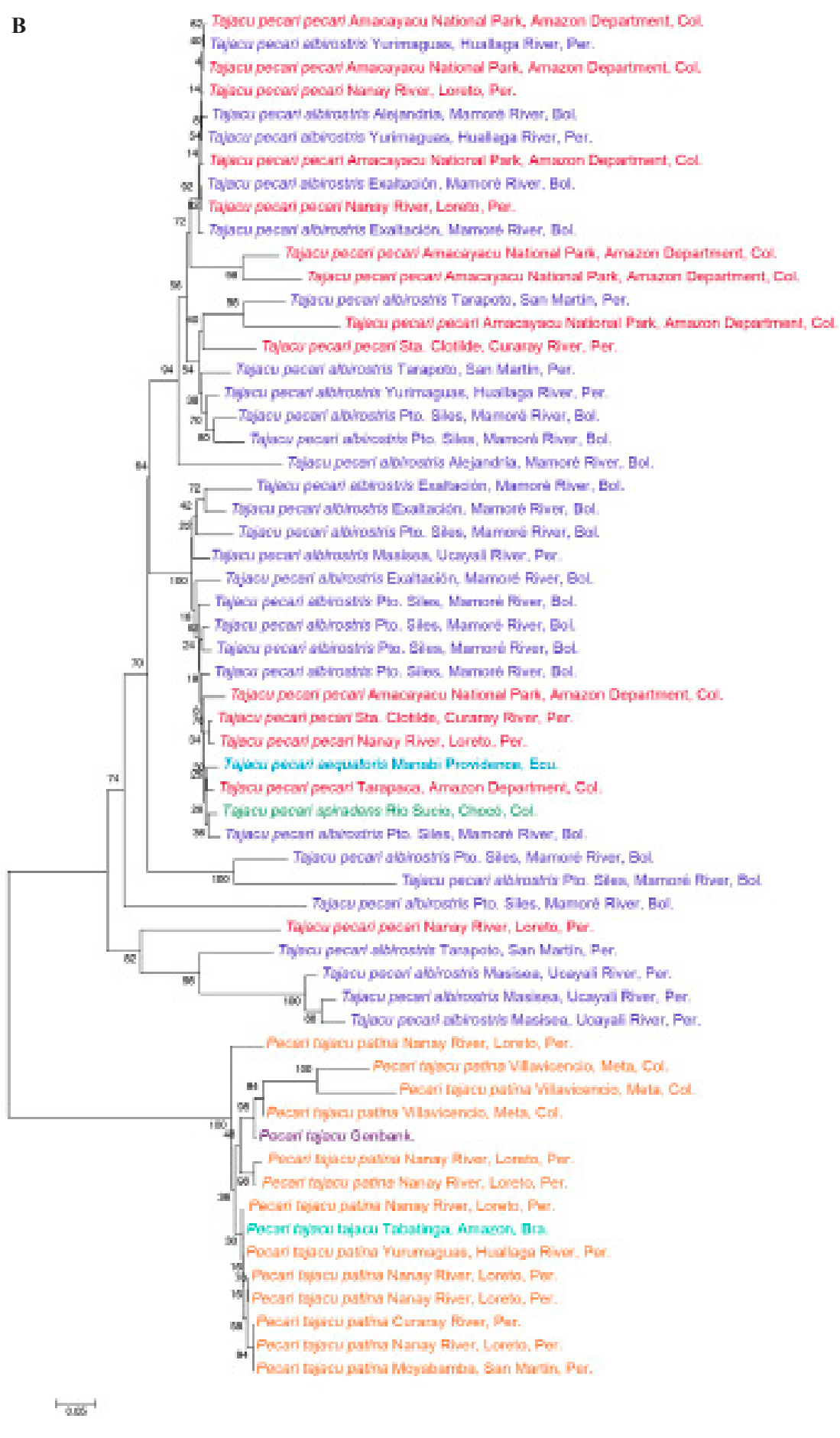


Table 4. Percentages of wrongly classified specimens of Tayassu pecari into other subspecies different from those morphological subspecies in which they were classified by means of the GeneClass 2.0 software.

A. Rannala and Mountain (1997) procedure: correctly assigned $60.30 \%$

T. pecari albirostris assigned as T. pecari pecari: $11.10 \%(4 / 36)$

T. pecari aequatoris assigned as T. pecari spiradens: $50 \%(1 / 2)$

T. pecari spiradens assigned as T. pecari albirostris: $33 \%(1 / 3)$

T. pecari pecari assigned as T. pecari spiradens: $16.22 \%(6 / 37)$

T. pecari pecari assigned as T. pecari aequatoris: $16.22 \%(6 / 37)$

T. pecari pecari assigned as T. pecari albirostris: $35.13 \%(13 / 37)$

B. Badouin and Lebrun (2000) procedure: correctly assigned $57.70 \%$

T. pecari albirostris assigned as T. pecari pecari: $8.33 \%(3 / 36)$

T. pecari aequatoris assigned as T. pecari spiradens: $50 \%(1 / 2)$

T. pecari spiradens assigned as T. pecari albirostris: $33 \%(1 / 3)$

T. pecari pecari assigned as T. pecari spiradens: $27.03 \%(10 / 37)$

T. pecari pecari assigned as T. pecari aequatoris: $13.51 \%(5 / 37)$

T. pecari pecari assigned as T. pecari albirostris: $35.13 \%$ (13/37)

C. Paetkau et al. (1995) procedure: correctly assigned $62.80 \%$

T. pecari albirostris assigned as T. pecari pecari: $8.33 \%(3 / 36)$

T. pecari aequatoris assigned as T. pecari spiradens: $50 \%(1 / 2)$

T. pecari aequatoris assigned as T. pecari pecari: $50 \%(1 / 2)$

T. pecari spiradens assigned as T. pecari albirostris: $33 \%(1 / 3)$

T. pecari pecari assigned as T. pecari spiradens: $16.22 \%(6 / 37)$

T. pecari pecari assigned as T. pecari aequatoris: $5.40 \%(2 / 37)$

T. pecari pecari assigned as T. pecari albirostris: $40.54 \%(15 / 37)$

D. Nei (1972) procedure: correctly assigned $56.40 \%$

T. pecari albirostris assigned as T. pecari pecari: $36.11 \%(13 / 36)$

T. pecari aequatoris assigned as T. pecari spiradens: $50 \%(1 / 2)$

T. pecari spiradens assigned as T. pecari albirostris: $33 \%(1 / 3)$

T. pecari pecari assigned as T. pecari spiradens: $13.51 \%(5 / 37)$

T. pecari pecari assigned as T. pecari aequatoris: $5.41 \%(2 / 37)$

T. pecari pecari assigned as $T$. pecari albirostris: $32.43 \%(12 / 37)$

E. Cavalli-Sforza and Edwards (1967) procedure: correctly assigned $64.10 \%$

T. pecari aequatoris assigned as T. pecari spiradens: $50 \%(1 / 2)$

T. pecari spiradens assigned as T. pecari albirostris: $33 \%(1 / 3)$

T. pecari pecari assigned as T. pecari spiradens: $18.92 \%(7 / 37)$

T. pecari pecari assigned as T. pecari aequatoris: $5.40 \%(2 / 37)$

T. pecari pecari assigned as T. pecari albirostris: $45.94 \%$ (17/37)

F. Goldstein et al. (1995) procedure: correctly assigned $55.10 \%$

T. pecari albirostris assigned as T. pecari aequatoris: $2.78 \%(1 / 36)$

T. pecari aequatoris assigned as T. pecari spiradens: $100 \%(2 / 2)$

T. pecari spiradens assigned as T. pecari pecari: $33 \%(1 / 3)$

T. pecari spiradens assigned as T. pecari aequatoris: $66.66 \%(2 / 3)$

T. pecari pecari assigned as T. pecari spiradens: $27.03 \%(10 / 37)$

T. pecari pecari assigned as $T$. pecari aequatoris: $5.40 \%(2 / 37)$

T. pecari pecari assigned as T. pecari albirostris: $45.94 \%$ (17/37)

When the likelihood ratio of Lhome/Lmax was estimated to determine the number of migrants for the first migration, the picture was very similar (Table 5) to the results described above. Twenty-seven migrant individuals were detected with the Cavalli-Sforza and Edwards (1967) genetic distance, whereas 35 migrant individuals were detected us- 
ing the $\delta \mu^{2}$ genetic distance. Moreover, the procedure by Rannala and Mountain (1997) detected 39.74\% (31/78) migrant individuals, with 11.11, 50.00, and 33.33, and 67.57\% of migrants identified as $T$. pecari albirostris, $T$. pecari aequatoris, $T$. pecari spiradens, and $T$. pecari pecari, respectively.

The 2 analyses via Structure 2.3 (Table 6, Figure 3) showed identical conclusions, although the results were better for the analysis using prior information with regard to geographic origins and subspecies (USEPOINFO $=1$; LocPrior $=1$ ). In both cases, the best results occurred when we considered admixture and migration of the 2 populations $(K=2$; estimated Ln probability of the data was -583.5 and -571.7 , respectively). The first population was confirmed by the T. pecari albirostris individuals from Bolivia and southern Peru, with high gene flow for the second population. This last one was confirmed by the individuals of the other 3 subspecies (i.e., T. pecari aequatoris, T. pecari spiradens, and T. pecari pecari), and it also showed elevated admixture for the first population.

Therefore, both mtDNA and microsatellites did not strongly agree with the putative morphological subspecies determined for the white-lipped peccary in northwestern South America.

Table 5. Possible percentage of migrant animals within different morphological subspecies to those they belonged by using the likelihood ratio Lhome/Lmax with the GeneClass 2.0 software.

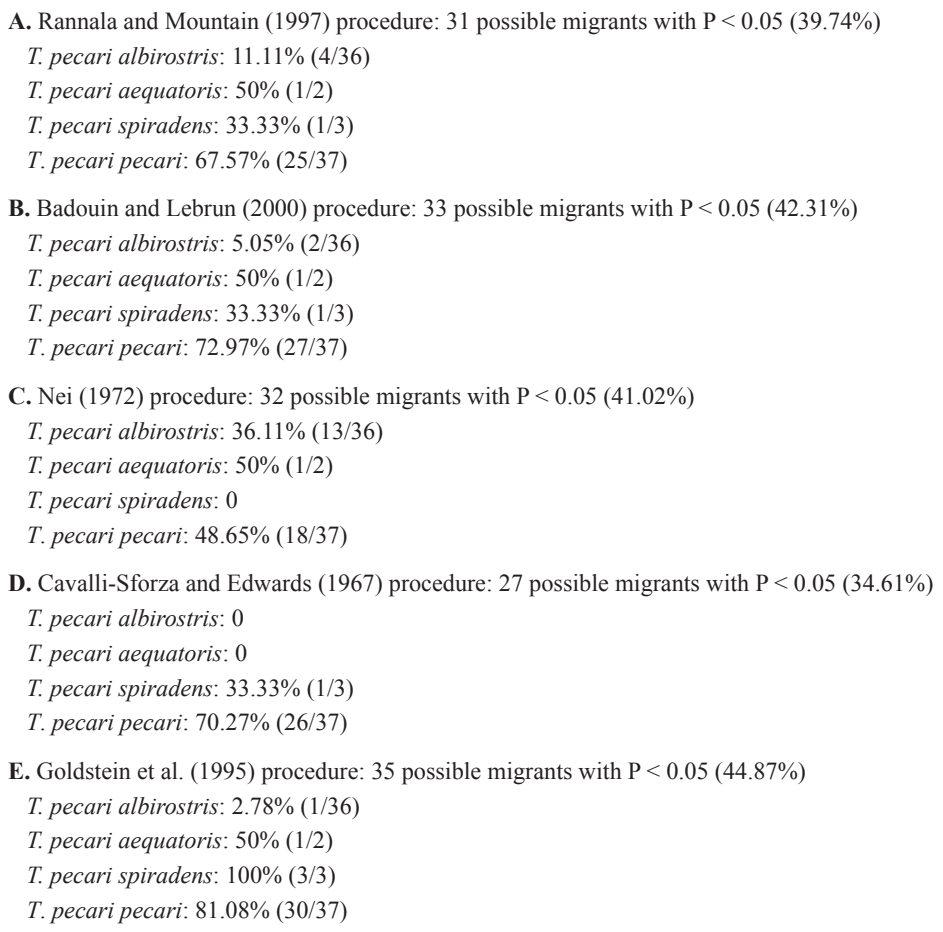

B. Badouin and Lebrun (2000) procedure: 33 possible migrants with $\mathrm{P}<0.05(42.31 \%)$

T. pecari albirostris: $5.05 \%(2 / 36)$

T. pecari aequatoris: $50 \%(1 / 2)$

T. pecari spiradens: $33.33 \%(1 / 3)$

T. pecari pecari: $72.97 \%(27 / 37)$

C. Nei (1972) procedure: 32 possible migrants with $\mathrm{P}<0.05(41.02 \%)$

T. pecari albirostris: $36.11 \%(13 / 36)$

T. pecari aequatoris: $50 \%(1 / 2)$

T. pecari spiradens: 0

T. pecari pecari: $48.65 \%(18 / 37)$

D. Cavalli-Sforza and Edwards (1967) procedure: 27 possible migrants with $\mathrm{P}<0.05(34.61 \%)$

T. pecari albirostris: 0

T. pecari aequatoris: 0

T. pecari spiradens: $33.33 \%(1 / 3)$

T. pecari pecari: $70.27 \%(26 / 37)$

E. Goldstein et al. (1995) procedure: 35 possible migrants with $\mathrm{P}<0.05(44.87 \%)$

T. pecari albirostris: $2.78 \%(1 / 36)$

T. pecari aequatoris: $50 \%(1 / 2)$

T. pecari spiradens: $100 \%(3 / 3)$

T. pecari pecari: $81.08 \%(30 / 37)$ 
Table 6 Assignation analyses with the Structure program. A. Without prior population information to assist clustering (USEPOPINF $=0$ ). The best result was with $K=2$ (i.e., 2 different populations). B. With informative geographical and subspecies priors (USEPOPINF $=1$ ). In addition, the best result was with $K=2 . K=$ number of populations; ELn = estimated Ln probability of the data. Results, indicating the greatest likelihood, are given in bold.

\begin{tabular}{llll}
\hline $\mathrm{A}$ & ELn & $\mathrm{B}$ & ELn \\
\hline $\mathrm{K}=1$ & -632.8 & $\mathrm{~K}=1$ & -632.7 \\
$\mathrm{~K}=2$ & $\mathbf{5 8 3 . 5}$ & $\mathrm{K}=2$ & $\mathbf{- 5 7 1 . 7}$ \\
$\mathrm{K}=3$ & -586.2 & $\mathrm{~K}=3$ & -675.1 \\
$\mathrm{~K}=4$ & -594.7 & $\mathrm{~K}=4$ & -575.4 \\
$\mathrm{~K}=5$ & -619.0 & $\mathrm{~K}=5$ & -575.9 \\
$\mathrm{~K}=6$ & -634.1 & $\mathrm{~K}=6$ & -576.5 \\
$\mathrm{~K}=7$ & -654.8 & $\mathrm{~K}=7$ & -576.7 \\
\hline
\end{tabular}

A.
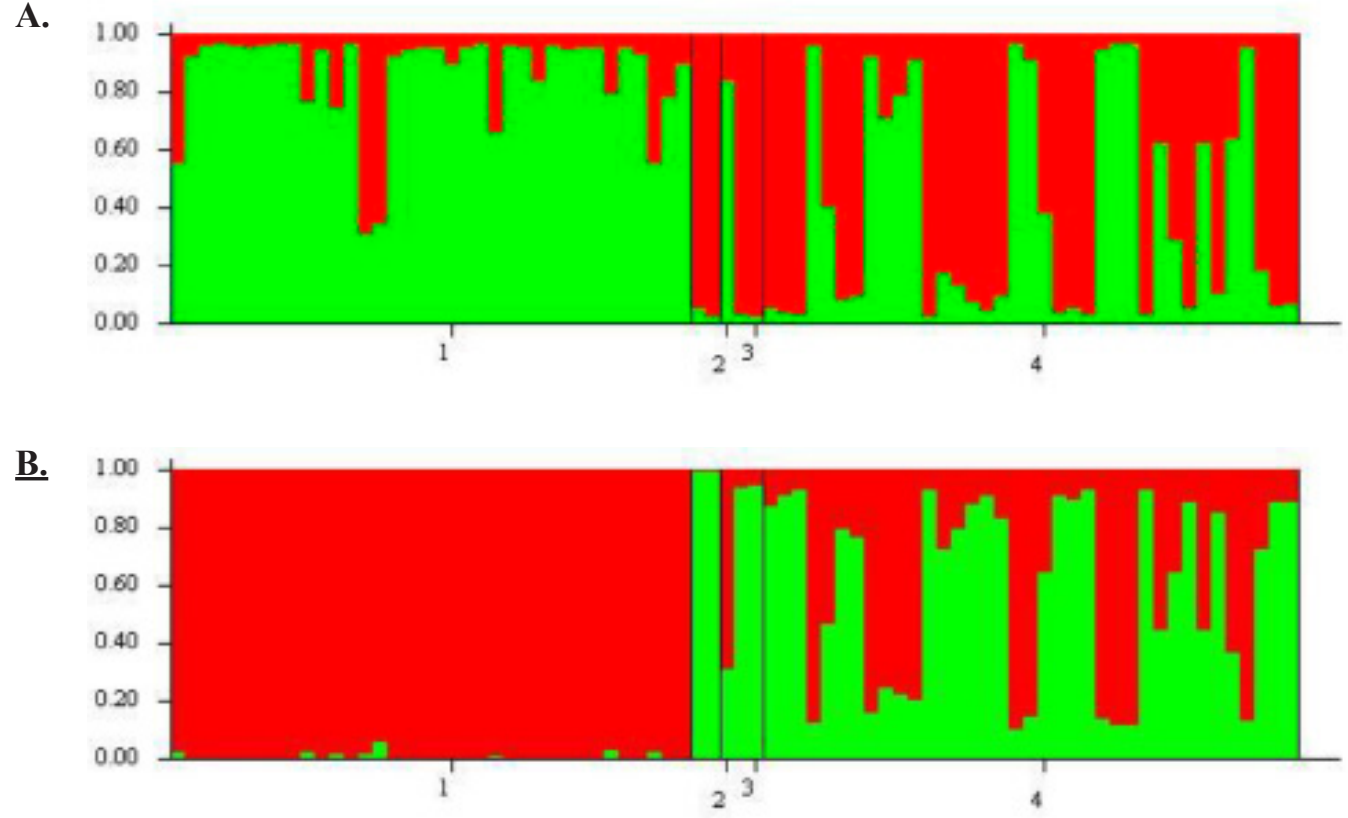

Figure 3. Assignation analyses with the Structure program. A. Without prior population information to assist clustering (USEPOPINF $=0$ ). The best result was indicated for $K=2$ (i.e., 2 different populations). B. With informative geographical and subspecies priors (USEPOPINF $=1$ ). In addition, the best result was identified for $K=2$ with extensive migration between them, especially from the first population into the second population. $1=$ Tayassu pecari albirostris; $2=$ T. pecari aequatoris; $3=T$. pecari spiradens $; 4=$ T. pecari pecari .

\section{Demographic genetics}

The mismatch distribution did not show a significant historical population change during the evolution of the northwest $T$. pecari population of South America. In addition, the diverse statistics employed did not detect significant demographic changes (Figure 4, Table 7), with the exception of Fu's $F_{\mathrm{S}}$ statistic $\left(F_{\mathrm{S}}=-9.087, \mathrm{P}=0.0052\right)$, which agreed with population 
expansion. Nevertheless, there was no clear picture of possible demographic changes during the history of the T. pecari population in northwestern South America.
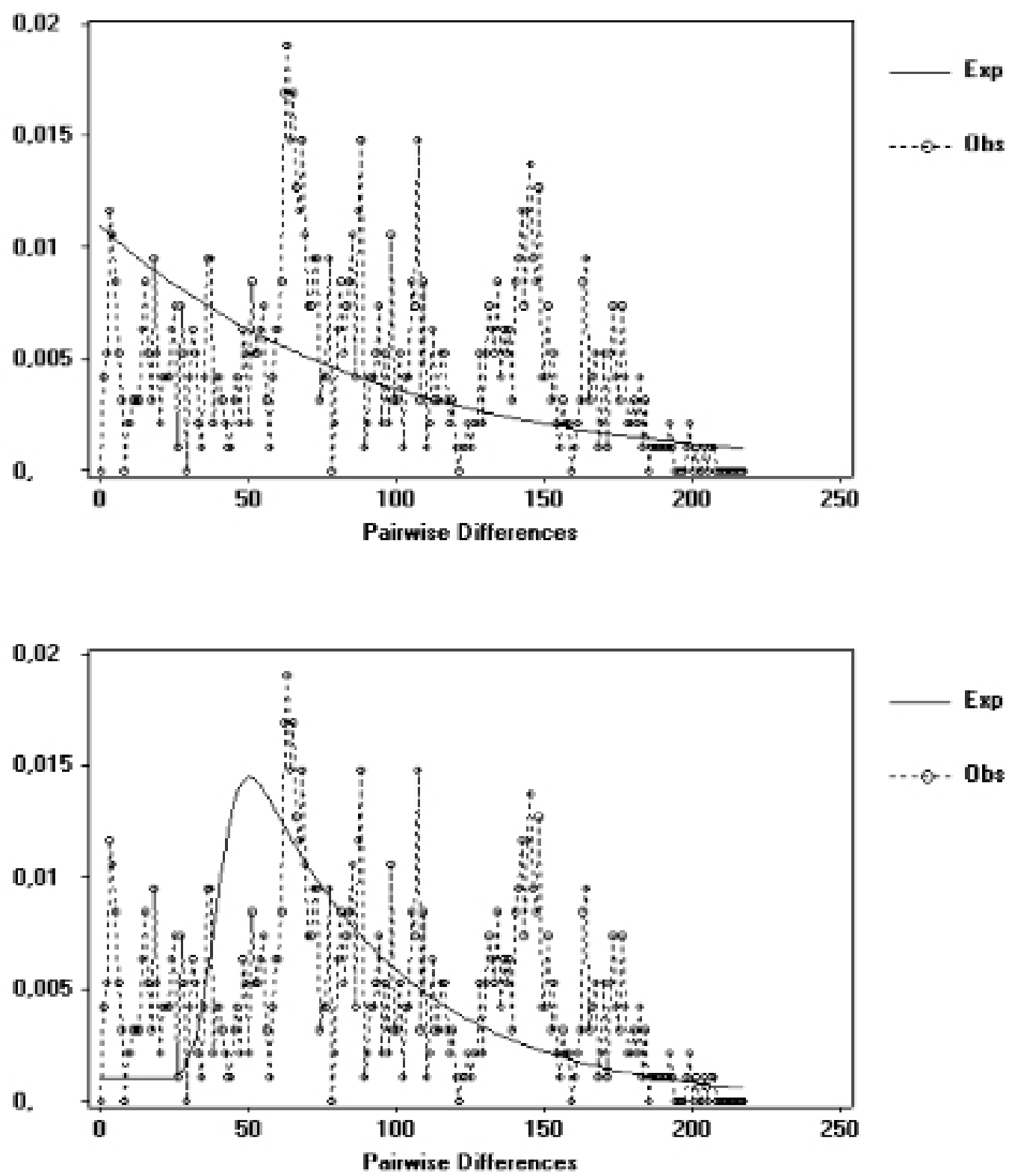

Figure 4. Mismatch distribution (pairwise sequence differences) at the mitochondrial control gene for the Tayassu pecari population analyzed from northwestern South America. A. Assumes a constant population size; B. Assumes population expansion. No clear evidence of population demographic changes was determined. 


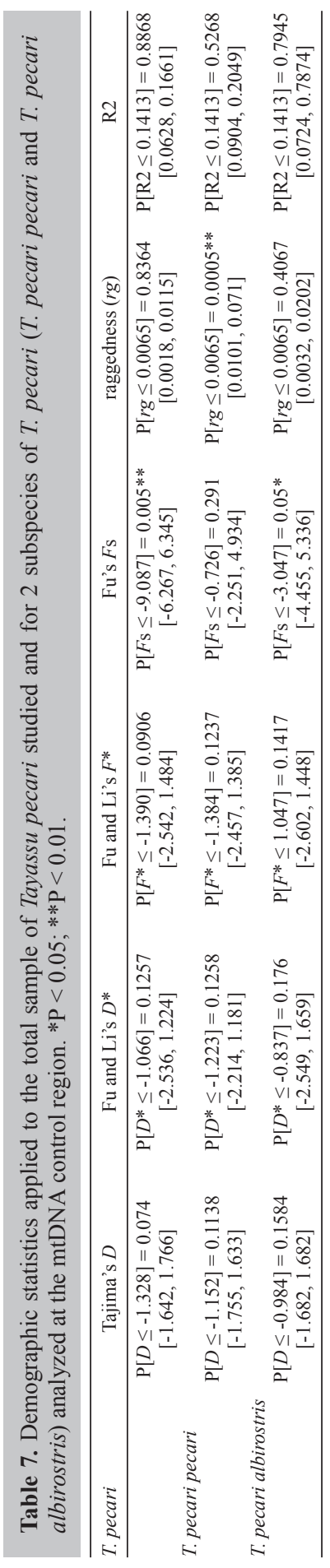




\section{DISCUSSION}

\section{Gene diversity}

The gene diversity found within the mtDNA control region was very high across all $T$. pecari samples and the 2 putative morphological subspecies analyzed. This can be explained by the relatively quick evolution of the mitochondrial sequence in comparison to other mitochondrial and nuclear markers. It can be also an indication that the historical effective population sizes in this species have been very large.

Our study with microsatellites determined a greater number of alleles in comparison to the findings by Biondo et al. (2011) for T. pecari (i.e., IGF1, 10 vs 3 alleles; SW857, 21 vs 3 alleles). This is logical because our sample represents a much wider area than the area covered in the study of Biondo et al. (2011).

The $H_{\mathrm{E}}$ for the microsatellites employed in the overall $T$. pecari sample was 0.667 , which indicates medium to high genetic diversity. The values were slightly lower for the 2 putative subspecies with the highest sample sizes, $T$. pecari pecari $\left(H_{\mathrm{E}}=0.616 \pm 0.392\right)$ and T. pecari albirostris $\left(H_{\mathrm{E}}=0.528 \pm 0.143\right)$. These gene diversity levels were very similar to the 2 T. pecari populations studied in the Brazilian Pantanal by Biondi et al. (2011) $\left(H_{\mathrm{E}}=\right.$ $0.57 \pm 0.25$ and $0.58 \pm 0.26$, respectively). The genetic diversity found for the second putative subspecies we studied was similar to that found for different Iberian pig breeds using a panel of 25 porcine microsatellites (Entrepelado: $H_{\mathrm{E}}=0.541$; Retinto Extremeño: $H_{\mathrm{E}}=0.503$; Lampiño: $H_{\mathrm{E}}=0.561$; Torbiscal: $H_{\mathrm{E}}=0.484$; Mamellado por Silvela: $H_{\mathrm{E}}=0.539$; Duroc: $H_{\mathrm{E}}=$ 0.534; pure Chato: $H_{\mathrm{E}}=0.290$; Martínez et al., 2000) and 11 European pig breeds $\left[H_{\mathrm{E}}\right.$ ranging from 0.35 to 0.60 in Basque (France) and Pietrain (Belgium), respectively; Laval et al., 2000]. The whole and $T$. pecari pecari samples showed higher levels of genetic diversity regarding these pig breeds and similar genetic diversity to that determined for the Cuban Creole pig $\left(H_{\mathrm{E}}=0.654\right.$ using a panel of 20 microsatellites). However, the levels of genetic diversity for T. pecari were clearly lower than those obtained for other pig breeds, such as the 18 Chinese indigenous breeds studied by Yang et al. (2003), whose values ranged from 0.700 to 0.876 .

\section{Genetic heterogeneity and no existence of subspecies within T. pecari in northwest- ern South America}

The mean genetic heterogeneity obtained using the microsatellites for the $T$. pecari sample was relatively small $\left(F_{\mathrm{ST}}=0.09\right)$. It was similar to the degree of genetic heterogeneity found by Yang et al. (2003) for 18 Chinese pig breeds $\left(F_{\mathrm{ST}}=0.077\right)$, and it was significantly lower than the genetic heterogeneity found by Laval et al. (2000) for 11 European pig breeds $\left(F_{\mathrm{ST}}=0.270\right)$. Thus, different European pig breeds yielded more genetic heterogeneity than that observed among the putative morphological T. pecari subspecies. These findings suggest that the putative subspecies of T. pecari described in northwestern South America are nonexistent from a molecular point of view. Moreover, the genetic heterogeneity found for the mtDNA control region was even lower than that detected via microsatellites, thus ratifying this conclusion.

Two molecular studies carried out on a microgeographic level with $T$. pecari agree with our findings. Campo-Gutiérrez (1999) analyzed 4 herds of this species at the Corcovado National Park, Sirena Sector, Costa Rica and estimated an $F_{\mathrm{ST}}$ value of 0.067 for isoenzymes 
and 0.058 for microsatellites. There were no significant heterogeneities and minimal genetic distances among the 4 herds. The gene flow estimations among these herds were $N_{\mathrm{m}}=3.41$ (isoenzymes) and $N_{\mathrm{m}}=3.93$ (microsatellites), which indicate high gene flow similar to that identified in the current study at a macrogeographic level $\left(N_{\mathrm{m}}=12.51, \mathrm{mtDNA}\right.$ control region; $N_{\mathrm{m}}=5.14$, microsatellites). A second study conducted by Biondo et al. (2011) analyzed 2 adjacent localities of T. pecari in the Pantanal (Brazil), which were $80 \mathrm{~km}$ in distance from each other. They sampled 100 individuals and genotyped 7 microsatellites. A significant $(\mathrm{P}<0.001)$ but low $F_{\mathrm{ST}}$ value (i.e., 0.02) was estimated, and a Bayesian analysis, with Structure, revealed a unique gene pool. Both sexes were dispersed similarly between both populations, which could augment gene flow among populations of $T$. pecari. In contrast to the absence of sex-biased dispersal in T. pecari, comparisons of the level of genetic differentiation between mtDNA and microsatellites revealed male-biased dispersal in populations of collared peccaries from Texas (Cooper et al., 2010). Thus, this second species could show higher levels of genetic heterogeneity than the white-lipped peccary. These 2 population genetics studies (i.e., microgeographic level) and the current study (i.e., macrogeographic level) revealed low genetic heterogeneity and elevated gene flow estimations among small and large geographically separated populations of T. pecari.

The following ecological and social characteristics of T. pecari could help us understand the results of our molecular genetics analyses. The white-lipped peccary prefers wetter lowland habitats, whereas the collared peccary is more restricted to the drier uplands in the Amazon, although the first species is also well adapted to the second habitat. T. pecari can use flooded forests and has a long dispersal range (Bodmer et al., 1997; Fragoso, 1999). However, it is for this reason that this last species is hunted to a greater extent than the collared peccary in flooded forests. In the upper forests of Tahuayo-Blanco, Peruvian Amazon, the hunting pressure for both peccary species was calculated at 33 individuals $/ 100 \mathrm{~km}^{2}$, while in the flooded forests of Maipuco, the hunting pressure for white-lipped and collared peccaries was calculated at 17 and 3 individuals $/ 100 \mathrm{~km}^{2}$, respectively (Bodmer et al., 1997). This species consumes a large quantity of fruits (i.e., 66\% of its diet; Bodmer et al., 1997); for this reason, it must move often, sometimes long distances, to meet its nutritional requirement. Altrichter and Almeida (2002) identified herd movements of $5 \mathrm{~km} /$ day in Costa Rica. In the Peruvian Amazon, Kiltie and Terborgh (1983) estimated that each herd could travel 10-15 km/day, have core areas of $\sim 60-200 \mathrm{~km}^{2}$ in size, and have an extremely high capacity to cross wide rivers with relative ease. Similar results were obtained by Fragoso (1999) in northern Brazil. He determined a home range of $109 \mathrm{~km}^{2}$ for herds of T. pecari; in the same area, however, P. tajacu herds had a home range of only $1 \mathrm{~km}^{2}$. Large migrations of the white-lipped peccary have been observed in Tahuayo (between the Ucayali and Yavari Rivers), Pacaya-Saimiria National Park (between the Ucayali and Marañon Rivers), and Manu National Park in southern Peru (Bodmer et al., 1997). During flooding in the Amazon, the few collared peccaries inhabiting these riverine forests have adapted by living in small refuge islands and changing their feeding habits. In contrast, $T$. pecari formed very large herds and migrated into expansive areas of riverine and flooded forests searching for food. Similarly, Fragoso (1999) determined a broader range of habitat use by the white-lipped peccary in comparison to the collared peccary. For example, one of the white-lipped peccary herds that he studied spent more time in riverine areas and savanna wetlands, while a second herd spent more time in palm wetlands and terra-firme forests. In contrast, collared peccaries spent all of their time in the terra-firme forest. Additionally, the sizes of the T. pecari herds were considerably larger in flooded forests than those in the 
uplands of Suriname. Moreover, white-lipped peccary herds have overlapping home ranges, with no reported territorial behavior (Fragoso, 1999), whereas in the collared peccaries, intraspecific territorial behavior among herds and patrol range boundaries have been observed (Fragoso, 1999). All of this data is in agreement with the fact that the white-lipped peccaries have larger bodies and herd sizes than those of the collared peccaries. Both of these characteristics could help them to deter predators, such as the jaguar, or move out of a predator's territory. However, in order to do this, large-sized food patches are needed to supply the large herds with the energy they need to move long distances into seasonal habitats, which contain abundant temporary resources (Fragoso, 1999). Such movements have been hypothesized to facilitate occasional genetic mixing among T. pecari herds (Altrichter and Almeida, 2002), which could be reflected in the results of our molecular analyses. All of these facts could explain why the genetic heterogeneity is very small among different $T$. pecari populations at the mtDNA marker and the relatively small genetic heterogeneity and low assignation percentages of the microsatellites in this species, with no indication of any existence of molecular subspecies. Another consequence of the social structure of the white-lipped peccary is that large areas with a mosaic of vegetation patches are needed to survive. Thus, it could be in greater danger probability of extinction than the collared peccary, which may better tolerate habitat disturbance with its small herd sizes, small area requirements, and subgrouping herd behaviors. This last fact can also assist in determining greater genetic heterogeneity among collared peccary populations and, thus, the possibility of a greater number of molecularly recognized subspecies for the collared peccary than that of the white-lipped peccary. For instance, Theimer and Keim (1994) were the first to investigate the genetic structure in P. tajacu in Arizona and Texas, and they claimed the existence of 2 differentiated molecular subspecies, which agree with the morphological subspecies $P$. tajacu sonoriensis in Arizona and P. tajacu angulatus in Texas. A second study on the molecular phylogeography of $P$. tajacu was undertaken by Gongora et al. (2006). These authors sequenced 31 exemplars of $P$. tajacu for the mtDNA control region and cytochrome $b$ genes and discovered 2 large clades, one conformed by North and Central American individuals (subspecies angulatus) and another by South American individuals (subspecies patira). They also found that several Colombian exemplars, classified as subspecies patira, were clustered within the North and Central American clade (i.e., subspecies angulatus). Therefore, a hybrid zone was discovered in Colombia between these 2 divergent clades. Thus, the molecular results could indicate opposing trends when determining molecular subspecies that correlate with the putative morphological subspecies in the whitelipped and collared peccaries.

\section{Demographic genetics}

The results obtained in this study did not detect noteworthy historical demographic changes in the northwestern South American T. pecari population. Only one test for mtDNA and several analyses with microsatellites (not shown here) yielded some evidence of population expansion for this species. However, the populations of T. pecari and P. tajacu are subjected to intense hunting pressure. Bodmer et al. (1997) estimated that the annual sustainable hunting quota in the Loreto Department in Peru was 26,040 and 32,494 individuals for the collared and white-lipped peccaries, respectively. For example, within the Loreto Department from 1992 to $1995,17,704 ; 31,577 ; 14,675$; and 19,505 skins of the collared peccary and 12,$222 ; 15,125 ; 7360$; and 13,351 skins of the white-lipped peccary were collected. In 1996, 
the Peruvian government approved an exportation quota of 25,000 and 15,000 skins for the collared and white-lipped peccaries, respectively. Ten years later, in 2006, the Peruvian government approved the following quota: a total of 70,784 and 48,268 skins for P. tajacu and T. pecari, respectively. Although the absolute number of animals hunted is very high, some studies have revealed that peccary populations can resist hunting pressure. For instance, Lleellish et al. (2007) analyzed the situation for the 2 peccary species in the area of Alto Purus-Ucayali (upper and middle Purus River basin in Santa Clara and the mouth of the Cocama River) and estimated an average density of 2.47 and 9.18 individuals $/ \mathrm{km}^{2}$ for $P$. tajacu and T. pecari, respectively. The calculated annual hunting pressures for that area were 0.57 and 1.14 individuals $/ \mathrm{km}^{2}$ for $P$. tajacu and $T$. pecari, respectively. Thus, the harvest model indicated that only $5 \%$ of the populations were subject to hunting, and both species were sustainably harvested. The hunting pressure for the collared peccary seems to be higher than that for the white-lipped peccary in many places. Nevertheless, the white-lipped peccary has lower rates of ovulation, fecundity, average litter size, and reproductive productivity than those of the collared peccary (Bodmer et al., 1997); therefore, it could be more susceptible to the effects of hunting than the collared peccary. Although the hunting pressure is high in this area, our molecular estimates of genetic diversity were very high for the mitochondrial marker and medium to high for the microsatellite markers employed. Thus, it appears that hunting pressure did not drastically reduced genetic diversity in T. pecari, and no bottlenecks were detected.

\section{Limitations}

This study represents the first approximation on this topic. We analyzed a very limited number of microsatellites and, thus, a greater number of microsatellites need to be analyzed to ensure adequate nuclear genetic diversity in this species is detected. Additionally, other molecular markers, such as MHC, autosomic and sexual chromosome introns, and other mitochondrial genes (e.g., $C O I$ and $C O I I)$ should be sequenced to determine, with better precision, the existence of different white-lipped peccary subspecies. It is also important that future molecular studies enclose representative samples of other putative subspecies and geographic areas, such as the T. pecari ringens from southern Mexico and Guatemala, Belize, and Honduras; T. pecari spiradens from Nicaragua, Costa Rica, and Panama; T. pecari pecari from northern Brazil and Guyanas; and T. pecari albirostris from southern Brazil and northern Argentina to determine possible molecular subspecies within T. pecari, bottlenecks, or demographic changes that could endanger local populations of this species.

\section{Conflicts of interest}

The authors declare no conflict of interest.

\section{ACKNOWLEDGMENTS}

The fist author thanks to Colciencias (\#Grant 1203-09-11239), Fondo para la Accion Ambiental (US-Aid) (\#Grant 120108-E0102141), and Pontificia Universidad Javeriana for economic sources. In addition, Unillanos is thanked for economical resources. Special thanks to Dr. Diana Álvarez, Pablo Escobar, Luisa Fernanda Castellanos-Mora, and Nicolás Lichilín, who all helped obtain peccary samples throughout Latin America. Additional thanks 
to the many people of the diverse Indian tribes in Peru (Bora, Ocaina, Shipigo-Comibo, Capanahua, Angoteros, Orejón, Cocama, Kishuarana, and Alamas), Bolivia (Sirionó, Canichana, Cayubaba, and Chacobo), Colombia (Jaguas, Ticunas, Huitoto, Cocama, Tucano, Nonuya, Yuri, Yucuna, Curripacos, and Desano), and Ecuador (Kichwa, Huaorani, Shuar, and Achuar).

\section{REFERENCES}

Altrichter M and Almeida R (2002). Exploitation of white-lipped peccaries Tayassu pecari (Artiodactyla: Tayassuidae) on the Osa Peninsula, Costa Rica. Oryx 36: 126-132.

Badouin L and Lebrun P (2000). An operational Bayesian approach for the identification of sexually reproduced crossfertilized populations using molecular markers. In: Proceedings of the international symposium on molecular markers for characterizing genotypes and identifying cultivars in horticulture (Dore C, Dosba F and Baril C, eds.). Montpellier, France, 6-9.

Benirschke K, Kumamoto AT and Merrit DA (1985). Chromosomes of the Chacoan peccary, Catagonus wagneri. J. Hered. 76: 95-98.

Biondo C, Keuroghlian A, Gongora J and Miyaki CY (2011). Population genetic structure and dispersal in white-lipped peccaries (Tayassu pecari) from the Brazilian Pantanal. J. Mammal. 92: 267-274.

Bodmer RE, Aquino R, Puertas P, Reyes C, et al. (1997). Manejo y uso sustentable de peccaries en la Amazonia Peruana. Occasional Paper of the IUCN Species Survival Commission No. 18. UICN-Sur, Quito, Ecuador and CITES, Geneve, Switzerland, pp. 102.

Campo-Gutiérrez H (1999). Variación y estructura genética dentro y entre grupos de chanchos de monte (Tayassu pecari) en el Parque Nacional Corcovado, Costa Rica. Master's Thesis. Universidad Nacional, Heredia, Costa Rica, 78.

Cavalli-Sforza LL and Edwards AWF (1967). Phylogenetic analysis: models and estimation procedures. Evolution 21: 550-570.

Cooper JD, Waser PM, Gopurenko D, Hellgreen EC, et al. (2010). Measuring sex-biased dispersal in social mammals: comparisons of nuclear and mitochondrial genes in collared peccaries. J. Mammal. 91: 1413-1424.

Falush D, Stephens M and Pritchard JK (2007). Inference of population structure using multilocus genotype data: dominant markers and null alleles. Mol. Ecol. Notes 7: 574-578.

Fragoso JMV (1999). Perception of scale and resource partitioning by peccaries: behavioral causes and ecological implications. J. Mammal. 80: 993-1003.

Fu YX (1997). Statistical tests of neutrality against population growth, hitchhiking and background selection. Genetics 147: 915-925.

Fu YX and Li WH (1993). Statistical tests of neutrality of mutations. Genetics 133: 693-709.

Gongora J, Morales S, Bernal JE and Moran C (2006). Phylogenetic divisions among Collared peccaries (Pecari tajacu) detected using mitochondrial and nuclear sequences. Mol. Phylogenet. Evol. 41: 1-11.

Gongora J, Biondo C, Cooper JD, Taber A, et al. (2011). Revisiting the species status of Pecari maximus van Roosmalen et al., 2007 (Mammalia) from the Brazilian Amazon. Bonn Zool. Bull. 60: 95-101.

Grubb P and Groves CP (1996). Los Dicotylidae del Neotrópico (Tayassu and Catagonus). Taxonomía y Descripción. In: Plan de acción y evaluación de la condición actual de los pecaríes (Olivier WLR, ed.). NYZS-The Wildlife Conservation Society and UICN-SUR, pp. 1-5.

Hudson RR (2000). A new statistic for detecting genetic differentiation. Genetics 155: 2011-2014.

Kiltie RA and Terborgh J (1983). Observations on the behavior of rain forest peccaries in Peru: why do white-lipped peccaries form herds? Zeitschrift fur Tierpsychologie 62: 241-255.

Kim KI, Lee JH, Li K, Zhang YP, et al. (2002). Phylogenetic relationships of Asian and European pig breeds determined by mitochondrial DNA D-loop sequence polymorphism. Anim. Genet. 33: 19-25.

Laval G, Iannuccelli N, Legault C, Milan D, et al. (2000). Genetic diversity of eleven European pig breeds. Genet. Sel. Evol. 32: 187-203.

Lleellish M, Ayala J, Manzur J and Matorela M (2007). El Circuito de Comercialización y los Procesos de Valor Agregado de Pieles de Pecaríes. Serie de Publicaciones de Flora y Fauna Silvestre. Instituto Nacional de Recursos Naturales, Lima, Perú, 1-14.

Martínez AM, Rodero A and Vega-Pla JL (2000). Estudio con microsatélites de las principales variedades de ganado porcino del tronco ibérico. Arch. Zootec. 49: 45-52.

Mayer JJ and Wetzel RM (1987). Tayassu pecari. Mammalian Species 293: 1-7.

Moran C (1993). Microsatellite repeats in pig (Sus domestica) and chicken (Gallus domesticus) genomes. J. Hered. 84: 
274-280.

Nei M (1973). Analysis of gene diversity in subdivided populations. Proc. Natl. Acad. Sci. U.S.A. 70: 3321-3323.

Paetkau D, Calvert W, Stirling I and Strobeck C (1995). Microsatellite analysis of population structure in Canadian polar bears. Mol. Ecol. 4: 347-354.

Paetkau D, Slade R, Barden M and Estoup A (2004). Genetic assignment methods for the direct, real-time estimation of migration rate: a simulation based exploration of accuracy and power. Mol. Ecol. 13: 55-65.

Posada D and Crandall KA (1998). MODEL TEST: testing the model of DNA substitution. Bioinformatics 14: 817-818.

Ramos-Onsins SE and Rozas J (2002). Statistical properties of new neutrality tests against population growth. Mol. Biol. Evol. 19: 2092-2100.

Rannala B and Mountain JL (1997). Detecting immigration by using multilocus genotypes. Proc. Natl. Acad. Sci. U.S.A. 94: 9197-9201.

Rogers AR and Harpending HC (1992). Population growth makes waves in the distribution of pairwise genetic differences. Mol. Biol. Evol. 9: 552-569.

Tajima F (1989). Statistical method for testing the neutral mutation hypothesis by DNA polymorphism. Genetics 123 : 585-595.

Tamura K, Peterson D, Peterson N, Stecher G, et al. (2011). MEGA5: molecular evolutionary genetics analysis using maximum likelihood, evolutionary distance, and maximum parsimony methods. Mol. Biol. Evol. 28: 2731-2739.

Theimer TC and Keim P (1994). Geographic patterns of mitochondrial-DNA variations in collared peccaries. J. Mammal. 75: 121-128.

Theimer TC and Keim P (1998). Phylogenetic relationships of the peccaries based on cytochrome $b$ DNA sequences. $J$. Mammal. 79: 566-572.

Todd NB (1985). Significance of a diploid number of 20 in the peccary Categonus wagneri. J. Hered. 76: 310.

Van Roosmalen MGM, Frenz L, Van Hooft P, De Iongh HH, et al. (2007). A new species of living peccary (Mammalia: Tayassuidae) from the Brazilian Amazon. Bonner zoologische Beiträge 55: 105-112.

Walsh PS, Metzger DA and Higuchi R (1991). Chelex 100 as a medium for simple extraction of DNA for PCR-based typing from forensic material. Biotechniques 10: 506-513.

Wetzel RM, Dubos RE, Martin RL and Myers P (1975). Catagonus, an "extinct" peccary alive in Paraguay. Science 189: 379-381.

Wright DB (1998). Tayassuidae. In: Evolution of tertiary mammals of North America (Janis CM, Scott KM, and Jacobs LL, eds.). Cambridge University Press, Cambridge, United Kingdom, 389-400.

Yang S-L, Wang ZG, Liu B, Zhang GX, et al. (2003). Genetic variation and relationships of eighteen Chinese indigenous pig breeds. Genet. Sel. Evol. 35: 657-671. 